\title{
“HISTÓRIA MEIO AO CONTRÁRIO...” LITERATURA INFANTIL, CONSCIÊNCIA CRÍTICA E FORMAÇÃO HUMANA EM UM CENTRO DE TRABALHO COMUNITÁRIO
}

\author{
"STORY IN REVERSE..." CHILDREN'S LITERATURE, CRITICAL AWARENESS AND \\ HUMAN EDUCATION IN A COMMUNITY CENTRE
}

\author{
“HISTORIA AL REVÉS...” LITERATURA INFANTIL, CONCIENCIA CRÍTICA Y \\ FORMACIÓN HUMANA EN UN CENTRO DE TRABAJO COMUNITARIO
}

\author{
Sheila Daniela Medeiros dos Santos ${ }^{1}$
}

\begin{abstract}
Resumo: Este artigo objetiva sublinhar a primazia da literatura infantil para a constituição do leitor crítico e para a formação humana em uma instituição de educação não-escolar, denominada Centro de Trabalho Comunitário, localizada no município de Goiânia, Goiás. Trata-se de uma pesquisa-ação, consolidada a partir de um projeto de extensão, fundamentada no referencial teórico da Psicologia Histórico-Cultural e da Pedagogia Histórico-Crítica. Para a concretização deste trabalho ofertou-se um minicurso semanalmente, durante um ano, às crianças que frequentavam o referido espaço institucional. Através deste trabalho foi possível constatar a relevância da literatura infantil no combate aos livros de autoajuda para crianças, contribuindo para a superação das concepções naturalizantes e discriminatórias que perpetuam e intensificam o conformismo, o preconceito e as desigualdades sociais.
\end{abstract}

Palavras-chave: Centro de trabalho comunitário; livros de autoajuda; literatura infantil.

\begin{abstract}
This article aims to underline the primacy of children's literature for the constitution of the critical reader and for the human formation in a non-school educational institution, called Centro de Trabalho Comunitário, located in the city of Goiânia, Goiás. It is an action research, consolidated from an extension project and based on the theoretical framework of Historical-Cultural Psychology and Historical-Critical Pedagogy. To carry out this work, a short course was offered once a week during one year to children who attended this institutional space during one year. Through this work, it was possible to verify the relevance of literature in the fight against children's self-help books, contributing to the overcoming of naturalizing and discriminatory conceptions that perpetuate and intensify conformism, prejudice and social inequalities.
\end{abstract}

Keywords: Community work centre; self-help books; children's literature.

Resumen: Este artículo tiene como objetivo subrayar la primacía de la literatura infantil para la constitución del lector crítico y para la formación humana en una institución educativa no escolar, denominada Centro de Trabajo Comunitario, ubicada en la ciudad de Goiânia, Goiás. Se trata de una investigación, consolidada a partir de un proyecto de extensión, basada en el marco teórico de la Psicología Histórico-Cultural y la Pedagogía Histórico-Crítica. Para llevar a cabo este trabajo, se ofreció un mini curso, una vez por semana durante un año a los niños que frecuentaban este espacio institucional. A través de este trabajo se pudo constatar la relevancia de la literatura infantil en la lucha contra los libros de autoayuda para niños, contribuyendo a la superación de concepciones naturalizadoras y discriminatorias que perpetúan e intensifican el conformismo, los prejuicios y las desigualdades sociales.

Palabras clave: Centro de trabajo comunitario; libros de autoayuda; literatura infantil.

\footnotetext{
${ }^{1}$ Universidade Federal de Goiás.
} 


\section{Introdução}

O título que designa este trabalho faz alusão à obra de literatura infantil com o mesmo nome, publicada pela primeira vez em 1978, de autoria da consagrada escritora brasileira Ana Maria Machado.

Nesta obra, a fórmula clássica "Era uma vez..." que norteia a tradição dos contos infantis figura somente ao final da narrativa dado que os personagens da história, cansados de "serem felizes para sempre" (MACHADO, 2019), decidem questionar valores, romper paradigmas e se emancipar de sua condição de dependência e submissão à ordem estabelecida, construindo as tramas e os dramas de sua própria trajetória.

Entretanto, os livros de autoajuda para crianças têm entrado de modo veemente no catálogo das editoras para cumprirem uma função social: a de fornecerem aconselhamentos às crianças e cederem lugar à redundância, aos imperativos, às ideias moralizantes, ao senso comum, às propostas terapêuticas, à visão utilitarista do conhecimento, enfim, às tipologias que recorrem ao senso comum.

Neste ínterim, o presente trabalho, ao edificar-se sob a apreensão em relação à disseminação e a onipresença dos livros de autoajuda para crianças, objetiva sublinhar a primazia da literatura infantil para a constituição do leitor crítico e para a formação humana em uma instituição de educação não-escolar, denominada Centro de Trabalho Comunitário, localizada no município de Goiânia, Goiás. Trata-se de uma pesquisa-ação (THIOLLENT, 2011), concretizada a partir de um projeto de extensão, com base no referencial teórico da Psicologia Histórico-Cultural (VIGOTSKI, 1999, 2007) e da Pedagogia Histórico-Crítica (SAVIANI, 2011).

A opção por esta abordagem de pesquisa se justifica por duas razões: primeiro, porque a pesquisa-ação envolve um processo investigativo edificado em uma problematização coletiva que intenciona lapidar as discussões e possibilitar a compreensão das práticas sociais e educacionais; segundo, porque a pesquisa-ação, conforme Elliott (2009) observou, permite superar as lacunas existentes entre a pesquisa educativa e a prática docente, de modo a favorecer profusamente mudanças sociais.

Neste sentido, de acordo com Thiollent (2011), há três elementos impreteríveis a serem focalizados que outorgam à pesquisa-ação um atributo inovador: o caráter participativo, a perspectiva democrática e a contribuição à transformação social.

A partir destas considerações, para concretizar este trabalho - além da realização das observações, das entrevistas com roteiro semiestruturado e dos diálogos informais (THIOLLENT, 2011) -, ofertou-se um minicurso constituído de atividades educativas e culturais, com foco na leitura de livros da literatura infantil, às crianças que frequentavam o referido espaço institucional.

Após considerar os pontos fulcrais deste estudo decidiu-se, como percurso inicial, caracterizar o contexto institucional onde o minicurso foi executado, com o intuito de elucidar e compreender a cotidianidade do mencionado campo de atuação social.

Na sequência, procurou-se demarcar o referencial teórico-metodológico que direcionou o olhar e o posicionamento dos membros da equipe executora do projeto de extensão, a fim de que fosse possível, em seção própria, sublinhar a primazia da literatura infantil para o desenvolvimento da criança e para a constituição do leitor crítico.

Por último, buscou-se tecer as considerações finais enfatizando que desnudar as conjecturas dogmáticas implícitas nos livros de autoajuda para crianças é de enorme pertinência, pelo fato de fazer irromper dispositivos analíticos e interpretativos apropriados capazes de desvelar o ideário neoliberal e os artifícios dos enunciados presentes neste contestável gênero direcionado às crianças. 


\section{$O$ contexto de atuação: elementos significativos}

De acordo com Saviani (2013), o primeiro quesito para intervir de modo coerente e substancial no campo da educação é conhecer e compreender o contexto histórico e social no qual se desenvolve a práxis educativa.

Ao considerar esta proposição, realizou-se uma breve caracterização do Centro de Trabalho Comunitário, ressaltando os elementos precípuos de sua composição. Estes elementos foram considerados durante todo o processo de planejamento, execução e avaliação do minicurso ministrado às crianças.

O Centro de Trabalho Comunitário, desde a sua fundação em 1993 por iniciativa de agentes da pastoral da Arquidiocese de Goiânia e de lideranças das comunidades localizadas no Setor Progresso, consolidou-se como uma organização associativa de natureza filantrópica, sem fins lucrativos, com o objetivo de promover ações assistenciais e socioeducativas à comunidade local e ao seu entorno.

O bairro onde localiza-se o Centro de Trabalho Comunitário possui praças arborizadas e recreativas, ruas pavimentadas, escolas públicas, pequenos comércios e unidades de assistência à saúde. Este bairro dispõe de avenidas que interligam as regiões norte, sul e oeste da cidade de Goiânia e, por esta razão, conta com uma circulação satisfatória de transporte público.

Apesar de a região passar por um grande processo de desenvolvimento e crescente especulação do mercado imobiliário em decorrência da criação de um shopping center nas proximidades, é possível encontrar vários moradores em situação de vulnerabilidade social vivendo em condições de pobreza extrema e de destituição de seus direitos básicos.

O Centro de Trabalho Comunitário funciona de segunda-feira a sexta-feira, das 7h30min às $17 \mathrm{~h} 30 \mathrm{~min}$ e aos sábados das $7 \mathrm{~h} 30 \mathrm{~min}$ às $11 \mathrm{~h} 30 \mathrm{~min}$, sendo que o período noturno é reservado para eventos comemorativos e palestras destinadas à população adulta.

O quadro de funcionários da instituição é composto por 14 integrantes: duas secretárias; duas cozinheiras; uma psicóloga; uma assistente social; uma professora de informática; um auxiliar de limpeza; um horticultor; dois educadores sociais (responsáveis por todas as atividades esportivas, recreativas e pedagógicas destinadas às crianças e aos adolescentes); duas professoras da educação básica (designadas para ministrar aulas para o curso de alfabetização de adultos e idosos); e uma coordenadora geral, quem os membros da comunidade interna e externa à instituição se referiam como "Irmã", pelo fato da mesma ter feito votos religiosos para uma vida fraterna em sociedade.

A instituição também conta, eventualmente, com os serviços desempenhados por voluntários de carreiras distintas, como: médicos, advogados, psicólogos e assistentes sociais, os quais realizam encaminhamentos diversos aos respectivos órgãos públicos do município.

$\mathrm{Na}$ época da realização deste trabalho, a instituição havia estabelecido convênios com a Secretaria Municipal de Assistência Social - SEMAS e com alguns programas governamentais, como: o Programa de Erradicação do Trabalho Infantil - PETI, o Programa Nacional de Acesso ao Ensino Técnico e Emprego - PRONATEC e o Serviço de Convivência e Fortalecimento de Vínculos - SCFV, agregado ao Serviço de Proteção e Atendimento Integral à Família - PAIF. Além destes convênios, a instituição mantinha parceria com outras organizações privadas e recebia doações de grupos empresariais através de ações de responsabilidade social.

Convém ressaltar que o Centro de Trabalho Comunitário também obtém recursos financeiros advindos: da realização mensal de um bazar de roupas e objetos; da comercialização de plantas homeopáticas e frutas desidratadas; e, ainda, da venda de sorvetes caseiros produzidos pela própria instituição. Os itens necessários para o funcionamento do bazar e para 
o comércio dos produtos homeopáticos e da sorveteria são provenientes de doações praticadas por pessoas físicas e/ou jurídicas.

Da mesma forma, a horta orgânica visa arrecadar fundos através da venda de hortaliças à comunidade, embora preserve como função predominante contribuir com o fornecimento das refeições (café da manhã, almoço e/ou lanche da tarde) à população diretamente atendida pela instituição.

Por conseguinte, o numerário angariado pelo Centro de Trabalho Comunitário através de financiamentos, doações e promoção de atividades e eventos, também é utilizado para: a conservação da estrutura física, a aquisição de produtos alimentícios e o pagamento dos funcionários.

No que se refere às atividades ofertadas à comunidade, a instituição disponibiliza cursos variados, como: alfabetização de adultos e idosos, costura industrial, manicure e pedicuro, cabeleireiro, maquiador, confeiteiro, recepcionista de eventos, informática, instrumento musical, fotografia, capoeira, yoga, ballet e futebol, entre outros eventualmente propostos por voluntários.

É imprescindível mencionar que a população específica atendida pelo Centro de Trabalho Comunitário (cerca de 800 pessoas), vivencia processos brutais de discriminação e exclusão social e sofre cotidianamente a violação de seus direitos básicos, os quais não são reconhecidos socialmente em razão das condições que lhes são negadas e/ou precariamente oferecidas de: habitação, alimentação, educação, assistência médica, segurança, trabalho, saneamento e justiça social.

Ademais, de acordo com o relato da coordenadora da instituição, o Centro de Trabalho Comunitário acolhe as crianças e os adolescentes no contraturno escolar, com o intuito de tirá-los das ruas e evitar que façam uso de drogas pertencentes ao grupo de inalantes (como cola de sapateiro) e/ou de outras substâncias psicotrópicas, uma vez que a instituição já registrou ocorrências desta natureza.

Sendo assim, o desenvolvimento do projeto de extensão no Centro de Trabalho Comunitário justificou-se pelo fato de acreditar que o domínio dos conhecimentos científicos, artísticos e filosóficos historicamente produzidos pelo gênero humano (GRAMSCI, 1995) é fundamental para lutar pelo reconhecimento dos direitos sociais, pela concretização da cidadania e por uma sociedade mais justa e igualitária. Como grande parte da população atendida pela Centro de Trabalho Comunitário não possui acesso a estes conhecimentos, o projeto de extensão efetivado adquiriu relevância pelo fato de contribuir com a radicação de uma consciência crítica, de tal forma que os processos alienantes não se sobressaíssem aos princípios de humanização (SAVIANI, 2007).

Outro elemento imprescindível de ser destacado e que instigou a realização deste trabalho, referiu-se ao fato de que na instituição havia apenas uma pequena biblioteca no interior de uma das salas, onde geralmente ocorriam os minicursos, as oficinas, as aulas de ballet $\mathrm{e}$ as refeições das crianças. Esta sala, que fazia parte de uma espécie de edícula anexa à casa principal, possuía um espaço de leitura improvisado, delimitado por uma cortina de chita suspensa em um varão, contendo um tapete felpudo com algumas almofadas e três prateleiras de madeira, as quais, por sua vez, dispunham de uma reduzida quantidade de livros infantis didáticos e paradidáticos. A maioria destes livros havia sido doados à instituição, de forma aleatória e sem qualquer critério. Por esta razão, foi possível identificar, em meio ao pequeno acervo existente, um número significativo de livros de autoajuda para crianças.

Em relação a este aspecto, cumpre lembrar que grande parte dos livros que chegavam às mãos das crianças eram produções de autoajuda. Isso porque, conforme pesquisa apresentada por Demo (2005), houve um aumento expressivo na comercialização de livros desse gênero nos últimos anos.

Deste modo, o presente trabalho almejou, sobretudo, conscientizar a comunidade que fazia parte do Centro de Trabalho Comunitário (coordenadora, funcionários, famílias e crianças), para os perigos deste gênero discursivo consubstanciado nas matrizes da nefasta 
política neoliberal, o qual fomentava o simulacro, a lógica meritocrática, a alienação e o conformismo em detrimento ao enfrentamento dos problemas individuais e coletivos.

Por estas razões, considerou-se à luz da Psicologia Histórico-Cultural e da Pedagogia Histórico-Crítica, que a privação de acesso aos conteúdos clássicos historicamente sistematizados e/ou a insistente tentativa de torná-los levianos, poderia converter-se em diáspora e estratégia de aprisionamento dos indivíduos às condições imediatas da realidade social.

Assim, parafraseando Saviani (2001), o domínio dos conhecimentos e dos instrumentos culturais constitui a essência para a participação política das classes populares na sociedade, a fim de que estas não fiquem em desvantagem às classes dominantes que se servem diretamente dos conteúdos da cultura para chancelar e consolidar a sua dominação e opressão.

\section{O modo de caminhar: rastros demarcados}

A análise dos aspectos delineados a partir da caracterização do Centro de Trabalho Comunitário permitiu elencar temáticas preocupantes da sociedade contemporânea que, pautadas em princípios consonantes com o ideário neoliberal, preconizavam discursos e práticas discriminatórias através dos livros de autoajuda para crianças, os quais perpetuavam e intensificavam o conformismo, o preconceito, as desigualdades e as injustiças sociais.

Estas temáticas específicas subsidiaram o planejamento e a realização de um minicurso constituído de atividades educativas e culturais, com base em livros de literatura infantil (contação de histórias, teatro de fantoches, confecção de brinquedos populares com sucata, pintura e colagem, dentre outras), cujo objetivo era propiciar uma visão crítica às crianças, a fim de que compreendessem os insidiosos ditames dos livros de autoajuda.

Convém enfatizar que, segundo Lajolo (2001), é preciso estarmos atentos àquilo que é literatura, pois no mundo atual há uma indústria sofisticada, exigente e de padrões estéticos elevados, que evidencia a tríade literatura/escritor/leis de mercado, a qual está preocupada tão somente com os aspectos econômicos.

Assim, as atividades que constituíram o minicurso foram discutidas, planejadas e avaliadas durante encontros que ocorreram semanalmente na Faculdade de Educação da Universidade Federal de Goiás. A equipe executora responsável pela elaboração e efetivação das atividades foi composta por 19 membros: uma coordenadora, duas instrutoras-supervisoras e 16 estudantes de graduação, sendo 15 estudantes do curso de Psicologia da Faculdade de Educação e um estudante do curso de Matemática do Instituto de Matemática e Estatística.

$\mathrm{O}$ minicurso ofertado às crianças durante o período de um ano $\left(2^{\circ}\right.$ semestre de 2018 e $1^{\circ}$ semestre de 2019) constituiu-se de 30 encontros distribuídos de modo a levar em conta o período de recesso/férias no início e no final do ano corrente. Sendo assim, ocorreram 17 encontros no $2^{\circ}$ semestre de 2018 e 13 encontros no $1^{\circ}$ semestre de 2019.

Em conformidade com a proposta do minicurso realizou-se: a pesquisa de obras literárias infantis, com viés crítico, que estivessem concatenadas às temáticas a serem desenvolvidas; o planejamento contínuo das atividades a serem viabilizadas no minicurso; e a participação efetiva dos membros da equipe executora (subdivididos em grupos de quatro integrantes) nos encontros semanais referentes ao minicurso implementado.

Posto isto, no $2^{\circ}$ semestre de 2018 elegeu-se, com embasamento nas demandas experienciadas pelas crianças, quatro temáticas: Afetividade, Relações de Gênero e Poder, Racismo e Desigualdade Social. Neste período trabalhou-se livros literários, como: $A h$, cambaxirra, se eu pudesse..., de Ana Maria Machado; Frida Kahlo: para meninas e meninos, de Nádia Fink; Quando as cores foram proibidas, de Monika Feth; Lápis cor de pele, de Daniela 
Brito; Quem tem medo do ridículo, de Ruth Rocha; Os direitos das crianças, de Ruth Rocha; dentre outros (SILVA; SANTOS, 2019).

Já no $1^{\circ}$ semestre de 2019 optou-se por priorizar três temáticas para o desenvolvimento das atividades no minicurso: Gênero, Preconceito e Racismo, e Desigualdade Social. Neste momento abordou-se obras literárias, como: Faca sem ponta, galinha sem pé, de Ruth Rocha; Malala, a menina que queria ir para a escola, de Adriana Carranca Meu crespo é de rainha, de Bell Hooks; O que teria na trouxa de Maria?, de Diane Valdez; Contos de Sacisas, de José Roberto Torero; dentre outros (SILVA; SANTOS, 2019).

Com base nestes livros literários infantis o minicurso materializou-se, encontro a encontro, reiterando que é precisamente pela literatura infantil que se faz possível transitar entre o paradoxal e o enigmático, para compreender e ressignificar o real a partir da convergência entre linguagem, imaginação, criatividade e ficção (ZILBERMAN, 2005).

\section{As vozes das crianças como elementos potentes}

A consecução do projeto de extensão, ao longo de um ano, possibilitou uma análise perscrutada de todo o processo vivenciado durante a implementação do minicurso e propiciou o surgimento consecutivo de outras questões passíveis de problematização.

Assim, o compromisso pactuado entre a universidade e a comunidade na qual se inseria o Centro de Trabalho Comunitário potencializou o embate imediato com uma realidade de profunda desigualdade e exclusão social. Ademais, a transitoriedade revelada pelas crianças que participaram do minicurso trouxe à tona as marcas do silenciamento e da violência física/simbólica vivenciados cotidianamente.

Com efeito, a construção e a ratificação de uma visão crítica e diligente sobre estes elementos, permitiram apreender o sentido da universalização dos conteúdos culturais, considerando que a apropriação dos mesmos é direito e premência de todo cidadão (SAVIANI, 2013).

A universidade, ao sintetizar a tríade ensino/pesquisa/extensão, ensejou o entrelaçamento entre princípios teóricos e prática pedagógica, de modo profundo e lacônico, promovendo a compreensão dos aspectos mais adversos da realidade experienciada pelas crianças, de tal maneira que foi possível buscar e fazer uso de conhecimentos científicos para a conscientização e transformação da referida realidade.

No que diz respeito ao trabalho desenvolvido durante o minicurso com as crianças, observou-se que elas demonstraram enorme interesse em realizar a leitura dos livros de literatura infantil selecionados em cada encontro.

Neste momento notou-se, conforme Britto (2012) e Lajolo (2005), que a palavra "leitura" não foi tomada simplesmente como uma habilidade da vida prática, mas foi considerada pelas crianças como uma atividade edificante, valorativa e humanizadora, que encerrava grande interação intelectual.

De fato, de acordo com Britto (2012), a leitura não deve pressupor meramente uma organização das formas de oralidade com léxico, sintaxe e prosódia próprios, mas deve apoiar-se sobre outra forma referencial, apartada do contexto imediato e vinculada às unidades de representação.

Nesta direção, a leitura envolve um processo emancipatório, de compreensão da realidade, cujo papel formativo e ético que lhe é implícito se destaca. Portanto, a leitura de livros literários infantis promove uma forma de pertencimento crítico ao mundo; um valor capaz de carregar um princípio de humanidade que implica, mais que um simples hábito, uma atitude (BRITTO, 2012).

Todavia, Britto (2012) também adverte para o fato de que esta perspectiva pode incorrer em nulidade, uma vez que o pertencimento do mundo é marcado por tensões e conflitos, em razão das desigualdades e disputa de valores e fazeres políticos que configuram a sociedade. 
Posto isto, o mero hábito de ler descompromissado, em uma situação em que o sujeito leitor é conduzido pelas circunstâncias e instigado por interesses pragmáticos, como sugere os livros de autoajuda, pode caracterizar uma condição de alienação, afinal,

[...] o que é alienado é automatizado, é feito mecanicamente, sem consciência dos processos de significação e, portanto, sem capacidade de ampliação de horizontes de vida. Em termos claros, a pessoa não tem controle ou consciência nem da atitude nem das coisas nela implicadas; não compreende o alcance e as consequências dos fatos e dos gestos (BRITTO, 2012, p. 30).

A partir destas considerações, observou-se que as crianças do Centro de Trabalho Comunitário, durante as discussões acerca da leitura dos livros de literatura infantil e das atividades dela decorrentes, procuraram questionar e propor diferentes soluções para as mais díspares situações da realidade abordada nas histórias narradas.

Nesta direção, o minicurso, ao versar sobre temáticas distintas com base em obras literárias infantis, possibilitou às crianças suplantarem concepções peremptórias, reivindicarem lugares de fala e expressarem seguramente o que haviam compreendido acerca do assunto trabalhado.

No que tange a este aspecto é possível citar uma situação, dentre as várias transcorridas no minicurso, em que os membros da equipe executora abordaram a temática "desigualdade social", fazendo uso de um livro de literatura infantil, e as crianças elaboraram cartazes contendo propostas políticas para enfrentar esta questão.

Do mesmo modo, em um dos encontros em que se discutiu "igualdade de gênero", as crianças se posicionaram de modo incisivo reconhecendo a necessidade de lutar pelos direitos das meninas/mulheres e de garantir a elas acesso à educação, saúde e segurança social.

É importante salientar que, embora o planejamento das atividades do minicurso tivesse ocorrido semanalmente de forma sistemática e fundamentada, os membros da equipe executora enfrentaram diversos imprevistos em razão das condições específicas e adversas inerentes às vivências das crianças, marcadas pela pobreza e pela violência.

Neste cenário, convém enfatizar o relevante papel do Centro de Trabalho Comunitário no sentido de intervir neste processo, propiciando o contato direto com a comunidade e reafirmando a importância da concretização do projeto de extensão como locus de produção e socialização de conhecimentos e de reconhecimento dos direitos das crianças.

Assim, a coalizão entre a universidade e o Centro de Trabalho Comunitário, viabilizada através da realização do projeto de extensão, ao mesmo tempo em que possibilitou mudanças nas crianças, promoveu transformações na própria instituição.

Portanto, o significado para as crianças de suas experiências de gênero, racismo, violência e exclusão social foram trazidos para a escuta e o olhar adulto de modo a permitir aos membros da equipe executora do projeto de extensão compreenderem a complexidade das vivências e dos vários papéis sociais imputados às crianças na vida familiar.

Por fim, os resultados deste trabalho evidenciaram que a extensão universitária, indubitavelmente, se consolidou como um espaço privilegiado de produção do conhecimento significativo para a superação das concepções naturalizantes e discriminatórias disseminadas na sociedade, as quais perpetuavam e intensificavam o conformismo, o preconceito e as desigualdades sociais existentes.

\section{Considerações finais}

Este trabalho discorreu sobre a imprescindibilidade de sublinhar a primazia da literatura infantil para a constituição do leitor crítico e para a formação humana em uma instituição de 
educação não-escolar, denominada Centro de Trabalho Comunitário, localizada no município de Goiânia, Goiás, como forma de obstar a proliferação dos livros de autoajuda para crianças.

Nesta perspectiva, com este trabalho, almejou-se enfatizar a pertinência de se trabalhar a literatura infantil em contraposição aos livros do gênero autoajuda para crianças, o qual se prolifera no mundo atual muitas vezes camuflado através de expressões forjadas nos catálogos das editoras como: "comportamento motivacional", "relações interpessoais", "superação", "convivência pessoal", "sentimentos", "boas maneiras", entre outras.

Não é demasiado asseverar, ao seguir as preleções de Vigotski (2001), que a literatura infantil deve ser considerada como uma forma de descortinamento da realidade e da ampliação de referências, primordiais para uma práxis pedagógica que possua como objetivo proporcionar condições para que se concretize a relação entre a apropriação dos elementos da cultura e o desenvolvimento psicológico da criança, transgredindo o utilitarismo pragmático que chancela o uso leviano dos livros de autoajuda para crianças em contextos de educação escolar e não-escolar.

Nesta ambiência, cabe ressaltar que enquanto a retórica adotada pelos livros de autoajuda caracteriza-se por enunciados prescritivos e conselhos direcionados às crianças, os livros de literatura infantil, contrariamente, coadunam e negociam embates entre os posicionamentos divergentes, questionam temáticas universais, pactuam com a produção do conhecimento e tecem argumentos acerca de diversos tipos de composições literárias: poesia, teatro, fábula, conto, mito, novela, cordel, entre outros.

Lajolo e Zilberman (2007), em instigantes estudos sobre este aspecto, salientam que a literatura infantil recorre a fantasias e metáforas para problematizar temas complicados, impulsionando a produção imaginária e, por conseguinte, proporcionando ao leitor atuar diretamente na formação de uma consciência de mundo e no processo de construção identitária, de tal maneira que lacunas provenientes de experiências restritas se concretizem no processo dialógico que fundamenta a leitura.

Portanto, na transformação em curso, a literatura infantil consolida-se como produção artística e cultural, de natureza social, capaz de conceber e ampliar novos olhares ao leitor, não apenas no que se refere à vivência estética, mas também no que diz respeito ao campo da existência humana, da consciência e do processo de apropriação do universo cultural e simbólico que implica a atividade imaginária (VIGOTSKI, 2009).

Para avançar esta discussão teórica, Abramovich (2006) pontua análises relevantes sobre a literatura infantil, alertando para o fato de que as obras literárias, ao terem como foco a ampliação dos horizontes cognitivos da criança, devem constituir um elemento basilar, mediador do conhecimento, no intuito de serem utilizadas como instrumento cultural, objeto estético, artístico, de fruição e, ainda, como recurso didático que forja novas experiências. Diante do exposto, advoga-se que a literatura infantil contribui para a formação crítica da criança ao propiciar, além da construção do conhecimento, o desenvolvimento de uma visão política e histórica que movimenta o exercício da cidadania.

Dadas estas considerações, este trabalho ensejou: a instauração de uma relação inextricável entre ensino, pesquisa e extensão; a democratização do conhecimento acadêmico que se produz com a pesquisa e a extensão, disponibilizando-o à comunidade do Centro de Trabalho Comunitário; o desenvolvimento da consciência social e política em estudantes e professores de graduação da Universidade Federal de Goiás; a qualificação dos processos formativos, com vistas a preparar profissionais preocupados com o reconhecimento dos direitos fundamentais do ser humano à cidadania; o estabelecimento dos mecanismos que relacionam os saberes acadêmicos da comunidade universitária da UFG aos interesses, necessidades e saberes populares do Centro de Trabalho Comunitário. 
Em face ao exposto, através deste trabalho, foi possível constatar o quão é impreterível chancelar, na organização societária atual, a relevância da literatura infantil no combate ao ponto estratégico de entroncamento dos livros de autoajuda para crianças, uma vez que estes fomentam processos que fazem com que os indivíduos aceitem, desde cedo e sem questionamentos, determinados valores relacionados ao Capital e às formas de dominação de uma sociedade Imperialista onde a pobreza e as injustiças sociais são, indubitavelmente, intensas e desumanas.

\section{Referências}

ABRAMOVICH, F. Literatura infantil: gostosuras e bobices. São Paulo: Scipione, 2006.

BRITTO, P. L. Leitura: acepções, sentidos e valor. Nuances: estudos sobre Educação, Presidente Prudente/SP, v. 21, n. 22, p. 18-31, jan./abr. 2012.

DEMO, P. Auto-ajuda: uma sociologia da ingenuidade como condição humana. Petrópolis: Vozes, 2005.

ELLIOT, J. Recolocando a pesquisa-ação em seu lugar original e próprio. In: GERALDI, C. M. G.; FIORENTINI, D.; PEREIRA, E. M. A. (Org.). Cartografias do trabalho docente: professor (a) - pesquisador (a). Campinas: Mercado de Letras, 2009. p. 137-152.

GRAMSCI, A. Os intelectuais e a organização da cultura. 9 ed. Rio de Janeiro: Civilização Brasileira, 1995.

LAJOLO, M. Literatura: leitores \& leitura. São Paulo: Moderna, 2001.

LAJOLO, M. P. Do mundo da leitura para a leitura do mundo. São Paulo: Ática, 2005.

LAJOLO, M.; ZILBERMAN, R. Literatura infantil brasileira. 6. ed. São Paulo: Editora Ática, 2007.

MACHADO, A. M. História meio ao contrário. 26. ed. São Paulo: Ática, 2019.

SAVIANI, D. Escola e democracia. 34. ed. Campinas: Autores Associados, 2001.

SAVIANI, D. Educação: do senso comum à consciência filosófica. 17. ed. Campinas: Autores Associados, 2007.

SAVIANI, D. Pedagogia histórico-crítica: primeiras aproximações. 11. ed. Campinas: Autores Associados, 2011.

SAVIANI, D. A pedagogia histórico-crítica, as lutas de classe e a educação escolar. Germinal: Marxismo e Educação em Debate, Salvador, v. 5, n. 2, p. 25-46, dez. 2013.

SILVA, R. N; SANTOS, S. D. M. Literatura infantil crítica e transforma-ação: uma experiência em um centro de trabalho comunitário. In: SIMPÓSIO DE ESTUDOS E PESQUISAS DA FACULDADE DE EDUCAÇÃO, 24., 2019. Anais eletrônicos: Universidade, formação e antiintelectualismo. Faculdade de Educação, Universidade Federal de Goiás, Goiânia, 2019, p. 671-681. 
Disponível em: https://drive.google.com/file/d/1ppyzKwvIGRf7a1o_1GP-Elt8v1_upXBP/view. Acesso em: 22 jun. 2021.

THIOLLENT, M. Metodologia da pesquisa-ação. 18. ed. São Paulo: Cortez, 2011.

VIGOTSKI, L. S. Teoria e método em psicologia. São Paulo: Martins Fontes, 1999.

VIGOTSKI, L. S. Psicologia da arte. 2. ed. São Paulo: Martins Fontes, 2001.

VIGOTSKI, L. S. A formação social da mente: o desenvolvimento dos processos psicológicos superiores. 6. ed.; São Paulo: Martins Fontes, 2007.

VIGOTSKI, L. S. A construção do pensamento e da linguagem. São Paulo: Martins Fontes, 2009.

ZILBERMAN, R. Como e por que ler a literatura infantil brasileira. Rio de Janeiro: Objetiva, 2005.

\section{Sobre a autora}

Sheila Daniela Medeiros dos Santos. Graduação em Pedagogia (FE/Unicamp), Mestre e Doutora em Educação (FE/Unicamp), Professora Associada (FE/UFG).

E-mail: sheiladmsantos@gmail.com. 